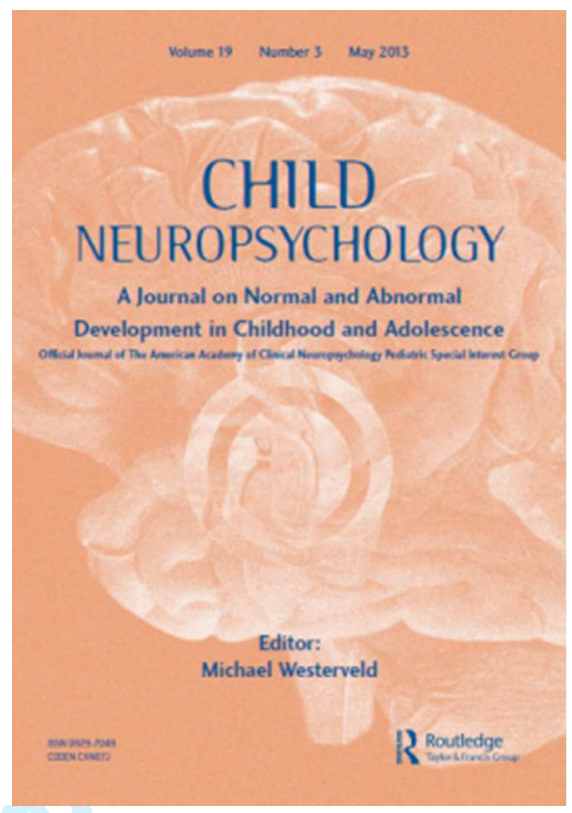

\title{
Assessment of executive function in ADHD adolescents: contribution of performance tests and rating scales
}

\begin{tabular}{|r|l|}
\hline Journal: & Child Neuropsychology \\
\hline Manuscript ID & CNY-OA 17-36.R2 \\
\hline Manuscript Type: & Original Article \\
\hline Date Submitted by the Author: & n/a \\
\hline Complete List of Authors: & $\begin{array}{l}\text { Krieger, Virginia; University of Barcelona, Psicologia Clínica i Psicobiologia } \\
\text { Amador-Campos, Juan Antonio; University of Barcelona, Psicologia Clínica i } \\
\text { Psicobiologia }\end{array}$ \\
\hline Keywords: & $\begin{array}{l}\text { ADHD symptoms, performance-based tests, behavioral rating scales, } \\
\text { executive function assessment, adolescence, diagnosis }\end{array}$ \\
\hline
\end{tabular}

\section{SCHOLARONE ${ }^{\text {ix }}$ \\ Manuscripts}


Assessment of executive function in ADHD adolescents: contribution of performance tests and rating scales

Virginia Krieger, Research MSc., is a Clinical child and adolescent psychologist and PhD student at Faculty of Psychology, University of Barcelona. Her research interests include assessment and treatment of children and adolescent with ADHD. vicky.krieger@neuf.fr

Juan Antonio Amador-Campos, $\mathrm{PhD}$, is a Clinical psychologist and professor of Psychological Assessment at Faculty of Psychology, University of Barcelona. His research interests include assessment and treatment of children, adolescents and adults with ADHD.jamador@ub.edu

Correspondence concerning this study should be addressed to Juan Antonio AmadorCampos, Passeig de la Vall d'Hebron, 171, 08035 Barcelona, Spain. Phone number: +34 9331251 32, Fax number: +34934021362. 


\section{Acknowledgements}

This work was partially supported by Grant FAKO-2009 from the Alicia Koplowitz Foundation, and the Agency for the Management of University and Research Grants from the Government of Catalonia, grant number 2014SGR1139.

We want to thank psychiatrists and psychologists of the Mental Health Center les Corts and Antonio Medina of the Salesians school of Badalona for their invaluable assistance in the sample recruitment. In the same way, the authors thank all adolescents, parents and teachers for their participation. 
1

2

3

4

5

6

7

8

9

10

11

12

13

14

15

16

17

18

19

20

21

22

23

24

25

26

27

28

29

30

31

32

33

34

35

36

37

38

39

40

41

42

43

44

45

46

47

48

49

50

51

52

53

54

55

56

57

58

59

60

Assessment of executive function in ADHD adolescents: contribution of performance tests and rating scales 


\begin{abstract}
Objective: this study aimed to analyze performance on measures of neuropsychological and behavioral executive functions (EF) in adolescents with attention deficit hyperactivity disorder (ADHD), and to evaluate the utility of performance-based tests for predicting scores on behavioral EF ratings. Method: 118 adolescents (75 ADHD and 43 controls) aged 12-16 years performed neuropsychological tests and completed a behavior rating scale of EF. Results: The ADHD group presented significantly lower scores than controls on Full Scale IQ (FSIQ) and all indexes of the WISC-IV, except the verbal comprehension index (VCI). The ADHD group had significantly lower scores on performance-based tests of working memory, planning and inhibition, and on EF rating scales. Scores on the cognitive EF working memory, planning and flexibility modestly predicted performance on behavioral EF. Conclusions: the results suggest that the combined use of performance-based tests and rating scales provides valuable complementary information that can improve the assessment of executive domains in
\end{abstract} ADHD.

Keywords: ADHD symptoms, performance-based tests, behavioral rating scales, executive function assessment, adolescence, diagnosis 
Introduction

Attention deficit hyperactivity disorder (ADHD) is one of the most frequently diagnosed psychopathological disorders during childhood and adolescence. It is characterized by the presence of symptoms of inattention, hyperactivity and impulsivity at a frequency and intensity inappropriate for the individual's age and level of development (APA, 2013). The combination and number of these symptoms can give rise to three types of presentation: predominantly inattentive (ADHD-I), predominantly hyperactive-impulsive (ADHD-HI) and combined (ADHD-C; APA, 2013). ADHD symptoms tend to diminish with age (Faraone, Biederman, \& Mick, 2006), especially hyperactivity and impulsivity (Pingault et al., 2015). During adolescence, inattention symptoms tend to be more frequent and intense than hyperactivity-impulsivity symptoms (Döpfner et al., 2015).

ADHD symptoms have been associated with deficits in executive functions (EF). EF involve separate but interrelated cognitive processes (Miyake et al., 2000) and are associated with the guidance and management of cognitions, behaviors and emotions (Gioia, Isquith, Guy, \& Kenworthy, 2000). The EF construct encompasses a wide range of processes such as inhibition, attention control, working memory, planning, flexibility, self-monitoring and initiation (Best \& Miller, 2010; Goldstein, Naglieri, Princiotta, \& Otero, 2013). Conventionally, EF have been evaluated using neuropsychological tests that involve measures of task performance. These performance-based tests include standardized measures typically based on accuracy or speed of response (Silver, 2014; Toplak, West, \& Stanovich, 2017). These measures are administered under standardized and carefully controlled conditions, and provide valuable information about a subject's performance on specific tasks in structured 
settings (Toplak et al., 2017). In addition, performance-based tests may be related with academic outcomes (i.e., math and reading ability) in children (Blair \& Razza, 2007).

Compared with community samples, children and adolescents with ADHD present deficits in a wide range of cognitive performance-based EF tests (Lambek et al., 2011; Willcutt, Doyle, Nigg, Faraone, \& Pennington, 2005) such as working memory (Martinussen, Hayden, Hogg-johnson, \& Tannock, 2005; Sowerby, Seal, \& Tripp, 2011), planning (Chiang, Huang, Gau, \& Shang, 2013; Dolan \& Lennox, 2013), flexibility (Mullane \& Corkum, 2007; Roberts, Martel, \& Nigg, 2017) and inhibition (Hart, Radua, Nakao, Mataix-Cols, \& Rubia, 2013; Rauch, Gold, \& Schmitt, 2012).

It has been suggested that children and adolescents with ADHD are a heterogeneous group; some, but not all, present deficits in EF (Nigg, Willcutt, Doyle, \& Sonuga-Barke, 2005; Wählstedt, Thorell, \& Bohlin, 2009) or exhibit specific problems in EF tasks according to their type of ADHD presentation (Guerts, Verté, Oosterlaan, Roeyers, \& Sergeant, 2005; Willcutt et al., 2005). Several studies examining the differences in types of presentation have found that children and adolescents with ADHD-C perform worse than those with ADHD-I in flexibility and inhibition (Roberts et al., 2017; Solanto et al., 2007), planning (Nigg, Blaskey, Huang-Pollock, \& Rappley, 2002; Rinsky \& Hinshaw, 2011) and working memory (Rosenthal, Riccio, Gsanger, \& Jarratt, 2006). Other studies do not indicate differences in performance between ADHD presentations on EF measures of planning, inhibition and flexibility, suggesting more similarities than differences in neurocognitive processes (Guerts et al., 2005; Martel, Nikolas, \& Nigg, 2007; Riccio, Homack, Jarratt, \& Wolfe, 2006). In individuals with ADHD-I, deficits have been reported in verbal and visuospatial working memory (Martinussen \& Tannock, 2006). Martel et al. (2007) also found in adolescents that weakness in a composite EF measure (i.e., flexibility and inhibition) was uniquely 
related to inattentive symptoms. Nigg et al. (2002) argued that cognitive EF performance differed little in the various ADHD presentations.

Another important point is that not all individuals with ADHD present deficits on performance-based tests of EF. This may be due to the highly standardized and structured assessment condition of clinical settings, which reduce the executive demands associated with everyday problems. That is, ADHD individuals may perform adequately because the examiner provides the guidance and control necessary to obtain optimal performance (i.e., in the form of rules specifying or constraining a task). In addition, these tasks are too brief to capture the temporal organization of the EF over longer periods of time or to tap several cognitive processes, including executive and non-executive skills, which makes interpretation of the EF difficult (Barkley and Murphy, 2011; Snyder, Miyake, \& Hankin, 2015). Therefore, EF evaluation o should not only involve performance-based measures but should also use behavioral measures or rating scales to assess an individual's functioning in everyday activities (Barkley, 2012; Gioia et al., 2000). It may be that rating scales of EF can better characterize deficits or competencies in goal-directed behaviors and everyday problem-solving in different life contexts (Barkley \& Murphy, 2011; Toplak et al., 2017). In addition, self and/or informant ratings of EF provide valuable information on performance on executive functioning based on observable behaviors (Isquith, Roth, \& Gioia, 2013; Toplak et al., 2017). This is important, considering the limitations of performance-based tests as objective measures of EF (Barkley, 2012).

Currently, a wide range of EF rating scales are available for the evaluation of everyday skills in children and adolescents in both home and school environments. Among the EF rating scales used in ADHD children and adolescents' samples are the Behavior Rating Inventory of Executive Functions (BRIEF; Gioia et al., 2000), the 
Barkley Deficits in Executive Functioning Scales (BDEFS-CA; Barkley, 2012), the Delis Rating of Executive Function (D-REF; Delis, 2012) and the Comprehensive Executive Function Inventory (CEFI; Naglieri \& Goldstein, 2013). The CEFI rating scales include self and informant rating forms that assess everyday EF skills in children and adolescents but, to our knowledge, no previous studies evaluating behavioral EF have used the CEFI in adolescents with ADHD.

Significant differences between groups with and without ADHD have been found on behavior EF rating scales (Long, Hill, Luna, Verhulst \& Clark, 2015; Weyandt, Oster, Gudmundsdottir, DuPaul, \& Anastopoulos, 2017). Thus, in groups of ADHD children and adolescents, deficits in EF have consistently been found compared with controls on the Metacognition Index (inhibition, working memory and plan/organize scales) and the shift scale scores of the BRIEF parents' and teachers' reports (Davidson, Cherry, \& Corkum, 2016; Toplak, Bucciarelli, Jain, \& Tannock, 2009). The ADHD-C presentation has been associated with difficulties on the emotional control, inhibit and monitor scales of the BRIEF reported by parents and teachers (McCandless \& Laughlin, 2007; Semrud-Clikeman, Walkowiak, Wilkinson, \& Butcher, 2010; Skogli, Egeland, Andersen, Hovik, \& Øie, 2014). The ADHD-I presentation has been associated with problems on the attention, initiation and planning EF scales of the Attention and Executive Function Rating Inventory teacher ratings (ATTEX; Klenberg, Jämsä, Häyrinen, Lahti-Nuuttila, \& Korkman, 2010). In sum, few significant differences between $\mathrm{ADHD}$ presentations are found in behavioral EF rating scales, with the exception of some of the scales (inhibition and emotion control) on the BRIEF parent and teacher forms (McCandless \& Laughlin, 2007; Semrud et al., 2010; Skogli et al., 2014). 
Overall, the performance of individuals with different ADHD presentations does not vary significantly over a wide range of neuropsychological measures and behavioral rating scales. In addition, behavioral rating scales of executive functioning are more sensitive to the executive deficits associated with ADHD symptoms than performancebased EF measures. Furthermore, the diversity in the profiles of EF deficits in ADHD indicates that the results of performance-based tests do not always correspond to executive functioning in activities of daily living (Seidman, 2006).

Some studies have shown very low or almost nonexistent correlations between performance-based tests and EF rating scales in child and adolescent samples, suggesting that these measures probably evaluate different constructs. For example, Bodnar, Prahme, Cutting, Denckla, and Mahone (2007) found poor correlations between the inhibition scale of BRIEF (parent report) and omission and commission errors, response time, variability and detectability on the Conners Continuous Performance Test -II (CPT-II; Conners, 2000) and the Test of Variables of Attention (TOVA; Greenberg, 1991). Vriezen and Pigott (2002) reported non-significant correlations between measures of cognitive flexibility (Wisconsin Card Sorting Test and Trail Making test) and EF ratings (BRIEF parent form).

Studies in ADHD children and adolescent samples have reported mixed results. For instance, Davidson et al. (2016) found a significant correlation between scores on the working memory BRIEF subscale (parent report) and working memory composite (Letter/Number and Finger/Windows subtest) of the Wide Range Assessment of Memory and Learning (WRAML2; Sheslow \& Adams, 2003). Shimoni, Engel-Yeger, and Tirosh (2012) reported low to moderate correlations between some scales of the BRIEF parent report (emotion control, working memory, plan, monitor and inhibit) and the Behavior Assessment of Dysexecutive Syndrome for Children total score (BADS-C; 
Emslie, Wilson, Burden, Nimmo-Smith, \& Wilson, 2003). Toplak et al. (2009) found that some performance-based tests of inhibition, shifting, working memory and planning EF were significantly but modestly correlated with the BRIEF parent and teacher reports of ADHD adolescents. A review of studies linking the BRIEF (parents and teacher reports) and the Dysexecutive Questionnaire (DEX self and other rating forms; Wilson, Alderman, Burgess, Emslie, \& Evans, 1996) with neuropsychological measures of inhibition, planning, flexibility and working memory found very weak associations between these two types of EF measure (Toplak, West, \& Stanovich, 2013).

Thus, performance-based tests and EF rating scales have provided important but different types of information. Performance-based tests evaluate the efficiency and maximum performance of cognitive processes and provide valuable information on performance in structured contexts (Toplak et al., 2017). EF ratings provide information about goal-directed behavior in everyday settings (Toplak et al., 2013; Toplak et al., 2017), and are useful for predicting occupational performance (Barkley \& Murphy, 2011), academic performance (Waber, Gerber, Turcios, Wagner, \& Forbes, 2006) and treatment improvement in ADHD groups (Turgay et al., 2010). For this reason, both types of information are necessary and complementary in ADHD assessment (Toplak et al., 2013).

In summary, working memory, flexibility, planning and inhibition are among the most frequently studied EF in children and adolescents with ADHD. Given the controversial relationship between measures of cognitive and behavioral EF, we hypothesized that: 1) the ADHD group would score lower than controls on performance-based measures of working memory, flexibility, planning and inhibition and on all scales of behavioral EF, but that there would be no differences between 
ADHD-I and ADHD-C groups, and 2) the scores of performance-based tests of EF would not be significant predictors of behavioral EF scores.

\section{Method}

\section{Participants}

The sample consisted of 118 adolescents, 75 diagnosed with ADHD and 43 controls, aged between 12 and 16 years. In the ADHD group 48 had diagnoses of ADHD-I (70\% male; age: $M=13.83, S D=1.36)$, and 27 ADHD-C (63\% male; age: $M$ $=13.19, S D=1.14)$; in the control group $55 \%$ were males (age: $M=13.42, S D=1.38$ ). Participants with ADHD were recruited from two child and adolescent mental health centers and a university psychological care clinic. The control group was recruited from a secondary school. The families were representative of the area where the care centers and the school are located. The majority of adolescents lived in two-parent families (90.5\%). Parents' educational level was distributed as follows: high school diploma (ADHD-I: $31.2 \%$; ADHD-C: $38.1 \%$; controls: $25.6 \%$ ), four years of college (ADHD-I: 36.2\%; ADHD-C: $16.6 \%$; controls: $38.4 \%$ ), education beyond college in professional training (ADHD-I: 9.2\%; ADHD-C: 32.8\%; controls: 11.6\%) and junior high and primary school (ADHD-I: 23.3\%; ADHD-C: 12.4\%; controls: 24.4\%). ADHD groups and controls did not differ significantly in terms of parents' educational level $\chi^{2}(12, N=$ $118)=12.01, p=.44$. All participants were born in Spain, except for seven who were adopted (5.9\%). The participants were recruited from January 2015 to November 2016 in a major urban area. Children with ADHD had at least one comorbid disorder besides ADHD (ADHD-I: 18.9\%; ADHD-C: 11.1\%) and had at least two or more other disorders (ADHD-I: 59.5\%; ADHD-C: 66.7\%). ADHD-I and ADHD-C did not show significant differences in comorbid disorders $\left.\chi^{2}(10, N=75)=12.36, p=.26\right)$. 
Participants in the ADHD group were required to meet DSM-5 criteria (APA, 2013). Diagnoses were made by a trained master's level clinical psychologist, on the basis of age of onset, duration, impairment and cross-situational manifestation of symptoms, through the Clinical Interview-Parent Report Form (Barkley \& Murphy, 2006), the results of the ADHD questionnaire (Amador Campos, Forns Santacana, Guàrdia-Olmos, \& Peró Cebollero, 2006) and the revised Conners-3 scales (Conners, 2008). Participants were classified as ADHD-I if they met all the criteria for inattention but not those for hyperactivity-impulsivity in both the Clinical Interview and the ADHD questionnaire, and had T-scores $\geq 65$ on the DSM inattentive scale and on the ADHD Index and $\leq 65$ on the DSM hyperactive-impulsive scale of the Conners- 3 scales. Participants were classified as ADHD-C if they met the criteria for inattention and hyperactivity-impulsivity in the clinical Interview and the ADHD questionnaire, and had T-scores $\geq 65$ on the DSM inattentive and hyperactive-impulsive scales and on the ADHD Index of the Conners-3, reported by parents and teachers. The control group participants had fewer than six symptoms of inattention and hyperactivity-impulsivity on the ADHD questionnaire, and T-scores $\leq 60$ on the DSM inattentive and hyperactive-impulsive scales and on the ADHD Index on the Conners-3, rated by parents and teachers. All potentially eligible cases were reviewed by a panel of three ADHD experts (i.e., two psychologists and one psychiatrist certified in clinical child and adolescent psychology). The unanimous agreement of the panel was required for the assignment of the participants to the ADHD or control groups.

Exclusion criteria were: full-scale intelligence quotient (FSIQ) $<85$ on the Wechsler Intelligence scale for Children Fourth Edition (WISC-IV; Wechsler, 2005), history of tics, neurological disorders or sensory impairments (seizures or brain injury), colorblindness, psychiatric disorders (autism spectrum disorder, motor or 
communication disorders, Tourette's syndrome, psychosis or bipolar disorder).

Participants taking stimulant and non-stimulant medication for ADHD symptoms (eight

ADHD-C and two ADHD-I) received prior approval from their referring physician to temporarily discontinue the medication for 24 hours prior to each assessment session. Before the beginning of each testing session, the parents or carers confirmed the suspension of ADHD medication for the required time.

Participation was voluntary in all cases. Participants and their parents or legal guardians were informed of the study objectives and provided signed informed consent before enrolling. Participants did not receive financial compensation for their participation. The study complied with the principles of the 1975 Declaration of Helsinki (revised in Tokyo in 2014).

\section{Measures}

\section{Clinical Interview-Parent Report Form}

The Clinical Interview-Parent Report Form (Barkley \& Murphy, 2006), which records information from children's or adolescents' parents, was used. This paper and pencil interview contains sections covering relevant developmental, medical, social and educational history. In addition, the interview provides DSM-IV diagnostic criteria (symptom counts, symptom onset and impairment settings) for childhood mental disorders (oppositional defiant, attention-deficit/hyperactivity disorder, conduct disorder, disruptive behavior disorder, anxiety and mood disorders).

\section{ADHD questionnaire}

The ADHD questionnaire (Amador Campos et al., 2006) consists of 18 items that record DSM-IV symptoms for ADHD. The frequency and occurrence for each symptom are scored on a four-point Likert scale ranging from 0 (not true at all, never, 
seldom) to 3 (Very true, often, very frequently). Self-report (ADHD-SR), parent (ADHD-P) and teacher (ADHD-T) forms were administered. Items rated 2 or 3 were taken to indicate the presence of ADHD symptoms.

\section{Conners-3 Rating Scales}

The Conners scales, 3rd edition (Conners-3; Conners, 2008) assess core symptoms of ADHD (inattentive and hyperactive/ impulsive), executive functioning, learning problems, peer and family relations as well as the most common comorbid complications in children and adolescents. Self-report (Conners-3 SR), parent (Conners$3 \mathrm{P}$ ) and teacher (Conners-3 T) long forms were used. Each item on the Conner-3 is rated on a 4-point scale ranging from $0=$ not true at all (never, seldom) to $3=$ very true (often, very frequently). In this study, the ADHD-Inattentive and Hyperactive-Impulsive DSM scales and the ADHD index T-scores were used as indicators of ADHD symptom severity.

\section{Neuropsychological testing battery}

\section{Intelligence}

The Wechsler Intelligence Scale for Children (WISC-IV; Wechsler, 2005). This is an individually administered intelligence test for people between the ages of 6-16;11. The FSIQ and the composite scores of verbal comprehension (VC), perceptual reasoning (PR), working memory (WM), and processing speed (PS) were recorded.

\section{Cognitive EF}

The spatial memory subtest (SSp) of the Wechsler nonverbal scale of ability (WNV; Wechsler \& Naglieri, 2011) assesses spatial working memory. The task consists of nine blocks positioned on a board. The examiner taps the blocks in a particular 
sequence. The subject has to reproduce a given sequence by tapping the blocks in the sequence that she/he has just seen (Span Forward; SpF index), or in backward order (Span Backward; $\mathrm{SpB}$ index). The raw scores of the $\mathrm{SpF}$ and $\mathrm{SpB}$ index were used.

Rey-Osterrieth Complex Figure Test (ROCF; Rey, 1941; Osterrieth, 1944). This test evaluates visuospatial constructional processes, planning strategy and visual memory with a task involving the copy of a complex figure (ROCF-C) and its immediate recall after a delay period (RCFT-M). The percentile scores of copy accuracy, time copy and immediate recall accuracy were recorded.

Porteus Maze Test (PMT; Porteus, 1973). This test evaluates the ability to anticipate, plan and inhibit behaviors. The subject is prompted to find his/her way through a series of 12 mazes of increasing difficulty, without lifting the pen or entering a dead end. The raw score of planning time (seconds) before starting to draw each maze, the qualitative $Q$ score and the total score (mental age score) were recorded.

Wisconsin Card Sorting Test (WCST; Heaton, Chelune, Talley, Kay, \& Curtiss, 1993). This test assesses reasoning, concept formation, problem solving and cognitive flexibility. The participant is required to find the correct sorting principle (color, shape, and number) without any prior instructions. The examiner's feedback on the sorting principle changes periodically and the subject must follow it in order to arrange the cards. The percentage of perseverative errors and conceptual level responses and the raw score of number of correct categories completed were recorded.

The Trail Making Test (tasks A and B: TMT A-B; Reitan, 1992). This test evaluates visual scanning, attention, and cognitive flexibility. It contains two tasks, A and B, with 25 circles distributed on a sheet of paper. Task A requires subjects to join up the circles numbered consecutively in ascending order, as quickly as possible. In task 
B they must join up numbers and letters, alternately, in ascending order (e.g., A-2, 2-B, until L-13). The total time (seconds) to complete trail B was recorded.

The d2 Test of Attention (Brickenkamp \& Zillmer, 1998). This test evaluates selective and sustained attention. It consists of a set of letters " $p$ " or " $d$ " which have some small dashes arranged individually or in pairs either above or below each letter. The subject must cross out only the "d"s with two dashes, regardless of whether the dashes appear above or below the letter, or one above and one below. Percentile scores of commission errors and total test effectiveness (TOT) were used. Table 1 lists the performance-based tests grouped by the cognitive EF they measure.

Insert Table 1 here

\section{Behavioral EF}

The Comprehensive Executive Function Inventory (CEFI; Naglieri \& Goldstein, 2013). This self-report rating scale assesses behaviors associated with executive functioning. Each item of the CEFI is rated on a 6-point scale ranging from $0=$ Never to $5=$ Always). The CEFI score has a mean of 100 and a standard deviation of 15. Higher standard scores indicate good executive functioning. Standard scores of the nine scales - attention, emotion regulation, flexibility, inhibitory control, initiation, organization, planning, self-monitoring and working memory - were recorded.

\section{Procedure}

The study was approved by the directors of the child and adolescent mental health centers, the university psychological care clinic, and the secondary school. The instruments were administered in three sessions lasting between 60 and 90 minutes each. They were administered in a fixed order as follows: First session (WISC-IV, ROCF), second session (WNV, PMT, TMT) and third session (WCST, d2, CEFI-SR). 
Once the evaluation process was completed, all participants received a written report with the results of the assessment. Participants in the ADHD group also attended a feedback session in the presence of parents and the reference health professional.

\section{Data Analysis Plan}

The chi-square test was used to examine differences between groups regarding sex, and ANOVAs were used to examine differences between groups in age, clinical symptoms and intelligence. Given that the four cognitive EF domains (working memory, planning, flexibility and inhibition, Table 1) grouped several indicators of performance with different score types (percentile, standard or raw scores, Table 1), these were transformed into Z-scores. In order to obtain a single score for each cognitive EF domain, a principal component analysis (PCA) was performed for each of these domains, forcing to extract one component. The factor scores for each cognitive EF factor were obtained using Bartlett's method of regression, and so they were considered as weighted Z-scores. Three separate MANOVAs were carried out to analyze differences between groups in cognitive abilities (WISC-IV, FSIQ and the four indexes), performance-based tests (working memory, planning, flexibility and inhibition factors) and the CEFI self-report rating scale. Univariate analyses were performed with Bonferroni or Games-Howell adjustment for multiple comparisons. Pearson correlations were conducted to explore the relationships between variables, taking into account the Cohen's correlation coefficients: $r=.10$ to .29 , low; $r=.30$ to .49 , moderate; $r=.50$ to 1.0, high (Cohen, 1988). In addition, Cohen's (1988) effect size criteria for eta squared

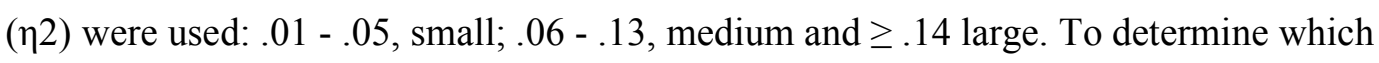
performance-based EF tests predicted scores of behavioral EF, hierarchical (blockwise entry) regression analysis were performed. Factor scores of performance-based EF tests (inhibition, working memory, planning and flexibility) were taken as independent 
variables and the nine CEFI scales as dependent variables. Working memory and inhibition FE are slightly more affected in children and adolescents with ADHD (e.g., Lambek et al., 2011). For this reason, working memory and inhibition factor scores were entered in the first step of the model; in the second step factor scores of planning and flexibility EF were entered.

There is substantial evidence of a significant relationship between general intelligence and performance-based EF measures (Brydges, Reid, Fox, \& Anderson, 2012; Dennis et al., 2009; Duggan \& Garcia-Barrera, 2015; Engelhardt et al., 2016). This is of particular interest, since ADHD has been significantly associated with both EF and IQ deficits (Dennis et al., 2009; Duggan \& Garcia-Barrera, 2015). For this reason, the FSIQ score was not included as a covariate in these analyses so as not to remove the significant variance in the performance on EF (e.g., Dennis et al., 2009; Miller \& Chapman, 2001). Further, since 'pure' ADHD is rare, and comorbidity is the rule in ADHD clinical samples, with very few exceptions (Owens \& Hinshaw, 2016; Yoshimasu et al., 2012), comorbidity was not considered as a covariate for further analysis.

\section{Results}

Table 2 shows demographic and descriptive statistics for ADHD and control groups and the ANOVA results with Bonferroni adjustment for multiple comparisons. The groups were equivalent in age $F(1,115)=2.33 p=.10$ and gender $\chi^{2}(2, N=118)=$ $2.21, p=.33$. Therefore, age and gender were not taken into account for further analysis. There were significant differences between the three groups (ADHD-I, ADHD-C and controls) in the DSM-inattentive, DSM-hyperactive-impulsive and the Conners-3 ADHD index: DSM inattentive scale [parents: $F(2,115)=97.56, p=.001$; teachers: $F(2,115)=118.33, p=.001$; self-reports: $F(2,115)=88.32, p=.001]$; DSM- 
hyperactive-impulsive [parents: $F(2,115)=46.46, p=.001$; teachers: $F(2,115)=$ 56.78, $p=.001$; self-reports: $F(2,115)=40.97, p=.001]$, and the Conners-3 ADHD index [parents: $F(2,115)=63.45, p=.001$; teachers, $F(2,115)=82.15, p=.001]$. After Bonferroni post hoc adjustment, no statistically significant differences were found between ADHD-I and ADHD-C groups in DSM inattentive scale according to parent, teacher and self-rating scores, but both these groups presented higher scores than controls.

Insert Table 2 here

Cognitive and behavioral executive functioning

Table 3 shows the descriptive statistics of the three groups in the four indices and the FSIQ of the WISC-IV and in performance-based and behavioral EF measures.

MANOVAs of the four indices and the FSIQ of the WISC-IV resulted in a significant group effect: Wilks' $\lambda=.727, F(10,222)=3.840, p=.001 ; \eta^{2}=.147$. Univariate analysis revealed significant differences between the three groups on the FSIQ of the WISC-IV $F(2,115)=17.863, p=.001, \eta^{2}=.237$; working memory, $F(2,115)=5.968$, $p=.003, \eta^{2}=.094$, and processing speed indices, $F(2,115)=9.614, p=.001, \eta^{2}=.143$. After Bonferroni post hoc adjustment, significant differences were found between controls, ADHD-I and ADHD-C in FSIQ. In working memory and processing speed, there were significant differences between controls and ADHD groups: controls had higher scores on these two indices and there were no significant differences between ADHD-I and ADHD-C.

MANOVAs of the cognitive EF factors (working memory, planning, flexibility and inhibition) resulted in a significant group effect: Wilks' $\lambda=.711, F(8,224)=$ $5.209, p=.001 ; \eta^{2}=.157$. Univariate analysis revealed significant differences between 
ADHD and control groups for working memory, $F(2,115)=8.372, p<.001, \eta^{2}=.127$, planning, $F(2,115)=6.172, p=.003, \eta^{2}=.097$ and inhibition, $F(2,115)=20.694, p<$ $.001, \eta^{2}=.265$. Bonferroni post hoc adjustment showed that ADHD groups scored significantly lower than controls, but there were no significant differences between ADHD-I and ADHD-C groups.

MANOVAs of CEFI resulted in a significant group effects: Wilks' $\lambda=.421$, $F(18,214)=6.432, p=.001 ; \eta^{2}=.351$. Univariate analysis revealed significant group differences for attention, $F(2,115)=44.608, p<.001, \eta^{2}=.437$; emotion regulation, $F(2,115)=17.193, p<.001, \eta^{2}=.230$; inhibitory control, $F(2,115)=26.734, p<.001$, $\eta^{2}=.317$; organization, $F(2,115)=52.185, p<.001, \eta^{2}=.476 ;$ planning, $F(2,115)=$ $37.388, p<.001, \eta^{2}=.394$; self-monitoring, $F(2,115)=31.431, p<.001, \eta^{2}=.353$ and working memory, $F(2,115)=26.944, p<.001, \eta^{2}=.319$. After Bonferroni post hoc adjustment, there were significant differences between controls and ADHD groups on attention, inhibitory control, organization, planning, self-monitoring and working memory scales although there were no significant differences between ADHD-I and ADHD-C groups. For the emotion regulation scale, significant differences were found between controls, ADHD-I and ADHD-C groups, with the highest scores for controls, followed by ADHD-I and ADHD-C.

For flexibility and initiation CEFI scales, the Brown-Forsythe $F$-ratio is reported because the assumption of homogeneity of variance was violated for both. Significant group differences were found for flexibility $\left(F(2,97.21)=16.890, p=001, \eta^{2}=.227\right)$ and initiation, $\left(F(2,89.05)=32.920, p=.001, \eta^{2}=.362\right)$. The Games-Howell post hoc test showed that ADHD groups scored significantly lower than controls, although there were no significant differences between ADHD-I and ADHD-C groups.

Insert Table 3 here 
Table 4 shows the Pearson correlations between scores of performance-based tests and self-rated scores of the CEFI and Conners-3 DSM scales for the ADHD and control groups. Since no significant differences were found between the ADHD-C and ADHD-I groups in performance-based tests and behavioral EF measures, except for the emotion regulation scale of the CEFI, the two groups are considered together.

Considering the ADHD group, correlations between cognitive and behavioral EF were low and not significant. In particular, correlations ranged from $[r(73)=-.23, p<.05$ between the flexibility factor and the attention scale of the CEFI to $r(73)=.28, p<.05$ between working memory factor and the emotion regulation scale of the CEFI]. No statistically significant correlation was found between cognitive EF factors and Conners-3 ADHD-Inattentive and ADHD-Hyperactive-Impulsive scales. The correlations between the CEFI and Conners-3 ADHD scales were low or moderate $[r$ $(73)=-.23, p<.05$ between flexibility of the CEFI ADHD-Inattentive on the Conners3 ; and $r(73)=-.41, p<.01$ between emotion regulation of the CEFI and ADHDHyperactive-Impulsive on the Conners-3].

For the control group, correlations between measures of cognitive and behavioral EF were low or moderate and not significant: the flexibility factor with selfmonitoring $(r(41)=.31, p<.05)$, and attention scales on the CEFI $(r(41)=.44, p<$ $.01)$. No significant correlations were found between cognitive EF factors and ADHDInattentive and ADHD-Hyperactive-Impulsive scales on the Conners-3. All correlations between CEFI scales and ADHD-Inattentive and ADHD-Hyperactive-Impulsive scales on the Conners-3 were moderate or high. In particular, significant correlations ranged from $[r(41)=-.32, p<.05$, between organization on the CEFI and Conners-3 ADHDHyperactive-Impulsive to $r(41)=-.79, p<.01$ between working memory of the CEFI and Conners-3 ADHD-Inattentive]. 
Insert Table 4 here

Relations between cognitive and behavioral EF

A sequential hierarchical multiple regression analysis was carried out to predict scores on the CEFI scales. In the first step, working memory and inhibition EF factor scores were entered into the model, and; in the second step factor scores of planning and flexibility EF. The diagnosis group was used as selection variable. Table 5 shows the B, SE B and $\beta$ values of hierarchical regression analysis only for significant predictors of scores on the CEFI scales.

Insert Table 5 here

In the ADHD group, scores on the emotion regulation scale were predicted by the working memory factor with $R^{2}$ of $.090[F(2,71)=3.148, p<.05 ; \beta=.310, t(71)=$ $2.430, p=.018]$; scores on the flexibility scale by the flexibility factor $[F(4,69)=$ $2.503, p<.05 ; \beta=-.246, t(69)=2.162, p=.034]$ with an $R^{2}$ of .127 ; scores on the selfmonitoring scale by the working memory factor $[\beta=.397, t(69)=2.909, p=.005]$ and by the planning factor $[\beta=-.348, t(69)=2.643, p=.010]$ with an $R^{2}$ of $.156[F(4,69)=$ $3.198, p<.05]$.

In the control group, scores on the attention scale were predicted by the flexibility factor with an $R^{2}$ of $.266[F(4,38)=3.440, p<.05 ; \beta=.454, t(38)=3.143, p$ $=.003]$ and scores on the flexibility scale by the planning factor $[\beta=.338, t(38)=$ $2.088, p=.044]$ and the flexibility factor $[\beta=.218, t(38)=2.140, p=.039]$ with an $R^{2}$ of $.225[F(4,38)=2.752, p<.05]$.

\section{Discussion}


This study analyzes the performance of two groups of adolescents with ADHD and a control group on different performance-based and behavioral EF measures.

With regard to cognitive ability, there were significant differences between ADHD-I, ADHD-C and control groups in full-scale IQ (FSIQ). The ADHD groups had lower FSIQ scores than the control group, as reported in other studies (e.g., Frazier, Demaree, \& Youngstrom, 2004). Taking into account the four main indexes of the WISC-IV, the ADHD groups exhibited significantly lower Working memory and Processing speed index scores than the control group, in agreement with the study by Mayes and Calhoun (2006). No significant differences were found between ADHD groups on any of the WISC-IV indexes, as reported in other studies (McConaughy, Ivanova, Antshel, \& Eiraldi, 2009). Interestingly, the ADHD-I group performed worse than the control group on working memory and processing speed, again in agreement with previous studies (McConaughy et al., 2009; Thaler, Bello, \& Etcoff, 2013).

Our first hypothesis was that ADHD groups would perform worse than controls on neuropsychological tests and on behavioral EF measures, and that there would be no differences between ADHD groups. In support of this hypothesis we found that the controls performed better than the ADHD participants on working memory, planning and inhibition cognitive EF factors. In particular, in the ADHD group the low scores in both visuospatial (spatial span of WNV and immediate recall of ROCF) and verbal working memory (Working memory index WISC-IV) were consistent with previous reports of impaired working memory processes in ADHD children (Martinussen et al., 2005; Martinussen, \& Tannock, 2006; Sowerby et al., 2011). In this sample, these findings are probably related to the high presence of inattention symptoms shared by the ADHD groups (ADHD-I and ADHD-C), as reported previously (Martinussen, \& Tannock, 2006). 
Although not all children with ADHD present problems in planning (Corbett, Constantine, Hendren, Rocke, \& Ozonoff, 2009), our results indicate that our ADHD groups had significantly more difficulties than their non-diagnosed peers on planning cognitive performance-based tests. A meta-analysis of 83 studies showed similar results on cognitive performance-based tests (i.e., Tower of Hanoi and Porteus mazes) in ADHD children and adolescents (Willcutt et al., 2005). Dolan and Lennox (2013) also found that adolescents with ADHD showed significant problems in planning EF, as assessed by the Stockings of Cambridge task (SOC; Owen, Downes, Sahakian, Polkey, \& Robbins, 1990).

The ADHD groups also performed significantly worse than the control group on the inhibition EF cognitive factor. These results were similar to those found in a metaanalysis including performance-based tests of inhibition such as Stroop, flanker and go/no-go tasks in ADHD groups and controls (Hart et al., 2013). In addition, examining inhibition EF with performance-based tests (i.e., local-global and go/no-go tasks) in a sample of children with and without ADHD, Rauch et al. (2012) reported significant inhibition difficulties in ADHD children compared with controls.

No significant differences were found between ADHD and control groups in measures of cognitive flexibility. Few studies have examined the relationship between ADHD and flexibility, and the results reported vary widely. In a meta-analysis, Frazier and colleagues reported that differences between ADHD and community samples on flexibility performance-based measures had smaller effect sizes (Frazier et al., 2004). In our study, we found no significant differences between ADHD and control groups on measures of flexibility derived from the WCST and from the TMT. In particular, performance on the WCST involves other EF such as working memory and inhibition (Mullane \& Corkum, 2007). This is especially relevant in the consideration of non- 
perseverative errors on the WCST; they involve both efficient and distraction errors, which are associated not just with flexibility but also with working memory and inhibition, and elicit different patterns of brain activation (Nyhus \& Barceló, 2009). Therefore, given the complexity of the mechanisms involved in the WCST, we should exercise caution with regard to the results obtained by the ADHD and control groups. As Barkley (2006) suggests, it is possible that the poor performance of children with ADHD on the WCST is related to difficulty incorporating the classification rule when responding rather than to difficulty discovering the classification rule itself.

As for the ADHD-I and ADHD-C groups, no differences were found in working memory, planning, flexibility and inhibition cognitive EF factors. These findings are in line with those of Guerts et al. (2005) who found no significant differences between ADHD-I and ADHD-C groups in EF measures of working memory (i.e., self-ordered pointing task; Petrides \& Milner, 1982), planning (Tower of London; Krikorian, Bartok, \& Gay, 1994), flexibility (Wisconsin card sorting test; Heaton, Chelune, Talley, Kay, \& Curtiss, 1993) or inhibition (i.e., the change task; Oosterlaan \& Sergeant, 1998). Willcutt et al. (2005) found no significant differences between ADHD groups in memory working, inhibition and planning EF tasks. Our study did not report any differences between ADHD groups, in agreement with Skogli et al. (2014) who found no significant differences between ADHD-C and ADHD-I in inhibition EF using the Color-Word Interference Test.

Furthermore, our findings are at odds with those of Rosenthal et al. (2006) who found that children and adolescents with ADHD-C performed worse on the working memory EF task of WISC-III (i.e., longest Digit Span backward) than children and adolescents with ADHD-I. Nor do our results agree with those of Chiang et al. (2013), who in a sample of ADHD children and adolescents found that the ADHD-I group had more 
visuospatial planning deficits on the Stockings of Cambridge task (CANTAB;

Cambridge Neuropsychological Test Automated Battery) than the ADHD-C group. This is probably because our sample was smaller than Chiang et al.'s, and this small sample size may have prevented us from detecting subtle differences between ADHD groups. Also, Nigg et al. (2002) indicated that the ADHD-I group had more problems in EF tasks of flexibility than the ADHD-C group and that boys with ADHD-C had more difficulties with the motor inhibition EF task than boys with ADHD-I.

Overall, our findings are in line with previous studies indicating EF deficits among adolescents with ADHD, especially in performance-based tests of inhibition, working memory and planning (Loo et al., 2007). Furthermore, ADHD-C and ADHD-I groups did not differ from each other across these cognitive EF domains, as other studies have reported (Geurts et al., 2005; Skogli et al., 2014). These results are in agreement with Nigg et al. (2002)'s suggestion that ADHD subtypes present few differences in cognitive EF, depending on the domain assessed.

As regards the behavior rating scales of EF, the results indicate that participants with ADHD had more difficulty than controls. This finding is consistent with previous research using information from parents and teachers on the BRIEF (Davidson et al., 2016; Skogli et al., 2014; Toplak et al., 2009), in which children and adolescents with ADHD were considered to be more impaired than controls. Interestingly, some studies using the BRIEF self-report have shown that ADHD groups report significantly more difficulties than non-ADHD groups in several areas of executive functioning (Long et al., 2015; Weyandt et al., 2017) as observed in the present study. Additionally, we found significant differences between the two ADHD groups only on the emotion regulation scale of the CEFI, in which the ADHD-C group presented greater difficulty. These results are consistent with previous reports that children with ADHD-C have more 
problems than those with ADHD-I and controls in emotional self-regulation (Maedgen \& Carlson, 2000). Difficulties in emotion regulation have been linked to ADHD, delayed maturation peaks, and reduced amygdala volume (Hoogman et al., 2017).

In summary, with regard to our first hypothesis, the results showed that ADHD groups had lower scores than controls on performance-based measures of cognitive (working memory, planning and inhibition) and behavioral EF (CEFI scales). In particular, the large effect size (partial eta squared, Cohen, 1988) in almost all CEFI scales suggests that these rating scales may be useful for identifying behavioral EF deficits in adolescents with ADHD, but less useful for differentiating between presentations of ADHD, except for the emotion regulation scale. Thus, measures of cognitive and behavioral EF provide relevant information on different aspects of executive functioning (Shimoni et al., 2012; Toplak et al., 2009) which may be useful in the neuropsychological and behavioral characterization of children and adolescents with ADHD. Our findings corroborate the view of Willcutt et al. (2005) that 'EF weaknesses are neither necessary nor sufficient to cause all cases of ADHD’ (p. 1343).

Regarding the low range of correlations between cognitive EF measures and inattentive and hyperactive-impulsive symptoms (Conners-3 self-rating DSM-scales), our findings are consistent with those of Toplak et al. (2009), who found no significant associations between performance-based EF tests and K-SDADS-PL inattention and hyperactivity/impulsivity scales. As for the strength and direction of the correlations between self-rating on the CEFI and the Conners-3 in the ADHD and control groups, the results suggested significant associations between the CEFI scales and both inattentive and hyperactive-impulsive symptoms. These results corroborate those reported for the BRIEF and BASC inattention-hyperactivity scales (McCandless \& O'Laughlin, 2007). In particular, the pattern of fairly high and negative correlations 
between the CEFI and Conners-3 rating scales observed in the control group suggests that adolescents respond consistently to both questionnaires and that there is also some overlap in the item content. Compared to the control group, the ADHD group had a different correlation pattern, with few significant correlations between the two rating scales, which may indicate the tendency of ADHD adolescents to respond less consistently. The pattern of few and low or moderate correlations between cognitive and behavioral EF measures was quite modest but significant. These results are consistent with those presented by Toplak et al. (2013), who suggested that the relationships between performance-based tests and rating scales (BRIEF) are extremely weak. Overall, in the ADHD group, the correlation analysis indicated a slightly inconsistent response pattern between EF measures (performance-based and rating scale) and ADHD symptoms. In addition, the few significant correlations between performance-based and behavioral EF measures indicated that they probably measure different aspects of executive functioning. These findings indicate that the joint use of performance-based measures and rating scales of behavioral EF and ADHD symptoms is probably necessary for a more comprehensive assessment of ADHD in adolescents.

Our second hypothesis was that scores on performance EF measures would not be significant predictors of behavioral EF measures. The findings partially confirm our hypothesis, since the regression analysis showed that working memory, flexibility and planning EF factors predicted scores of only a few CEFI scales. Specifically, in the ADHD group, the working memory EF factor significantly predicted emotion regulation and self-monitoring behavioral EF, and flexibility and planning EF factors significantly predicted flexibility and self-monitoring behavioral EF. In the control group, flexibility and planning EF factors predicted scores on attention and flexibility scales respectively. 
Overall, a heterogeneous and reduced pattern of predictions emerged between cognitive and behavioral measures.

Together, these results suggest that in ADHD and control groups, the EF factors of flexibility, planning and working memory predict a significant but small amount of the variance in behavioral EF measures. These results are in line with Toplak et al. (2009)'s findings of modest relationships between cognitive tasks and BRIEF rating scales (parent and teacher reports). Overall, with respect to our second hypothesis, the results suggest that performance-based EF tests are not likely to be significant predictors of behavioral EF measures in adolescents with ADHD. These results may be associated with the heterogeneity of executive functioning in ADHD and with the conclusion of Miyake and colleagues (2000) that EF can show unity and diversity.

Taken together, these findings appear to reflect the complex interplay between cognitive and behavioral executive processes and ADHD symptoms in everyday life settings (Davidson, Amso, Anderson, \& Diamond, 2006). Thus, the two types of measures tap different executive processes which can be accomplished more or less effectively depending on the demands of the settings. A performance-based test, applied in a structured setting, can provide valuable information about optimal performance and can therefore predict performance in similar settings, such as school tasks in the classroom. However, tests of this kind cannot accurately predict performance in goaldirected behavior in real-world settings, for instance in complex social situations. Everyday settings are less structured; the level of demand varies and there is no instruction from the evaluator. What is more, performance is estimated by the self or by other informants, a circumstance that does not guarantee maximum accuracy (Toplak et al., 2017). In addition, variables such as environmental cognitive demand and use of compensatory skills can mediate the relationships between cognitive and behavioral EF 
(Chaytor, Schmitter-Edgecombe, \& Burr, 2006). Thus, executive difficulties coupled with low environmental demands may not be reflected in executive problems in everyday life, and vice versa. In addition, in situations of neuropsychological assessment, the compensation skills that are used in everyday life cannot be applied (Chaytor et al., 2006).

From a clinical perspective, it is difficult to map a unique, generalizable executive profile for individuals with $\mathrm{ADHD}$, due to the marked heterogeneity that characterizes the neuropsychological and behavioral profiles associated with the deficit. Thus, clinical assessment of people with ADHD should combine the use of cognitive and behavioral EF measures. These measures provide complementary information in order to capture the nature of executive deficits across several settings (i.e., family, social and school), reduce the risk of clinical bias, and improve the individual characterization of deficits at the level of executive functioning. This information may be useful for developing intervention strategies that are ecologically more valid and facilitate the transfer of specific EF improvements to different areas of everyday functional difficulties in ADHD (Cortese et el., 2015). In summary, in the current study the ADHD group presented greater difficulty than the control group on performance-based tests and behavioral EF measures. There were no significant differences between the ADHD-I and ADHD-C groups. In addition, cognitive EF predicted little variance associated with behavioral EF, which may suggest that both measures tap different components of executive functioning.

This study has some limitations. For example, the ADHD group did not include participants with the hyperactive-impulsive presentation. Furthermore, the ADHD-C group was smaller than the ADHD-I group, a circumstance which may have prevented us from detecting small differences between ADHD groups. 
Among the study's strengths are the rigorous combination of information gathered from different informants (parents and teachers), through clinical interviews and rating scales in order to issue an accurate ADHD diagnosis. Significant deficits in several executive domains were also identified in ADHD participants with $\mathrm{EF}$ performance-based tests and rating scales. In addition, the CEFI scales are sensitive to ADHD symptoms and are useful to characterize the performance profile of executive behavioral functioning. Future research could explore the relationships between CEFI and other EF rating scales.

This study provides additional evidence of the relevance of using both types of measure in the assessment of ADHD since they can improve the understanding of the heterogeneity of neuropsychological impairments in ADHD adolescents.

In sum, the data provided here support the hypothesis of cognitive and behavioral EF difficulties in ADHD groups. The results extend previous findings by showing that cognitive performance-based tests and behavioral EF rating measures provide valuable, different and complementary information about behaviors related to ADHD. More widely, the data have implications for the combined use of performancebased tests and rating scales in the comprehensive assessment of executive functioning and behavioral characterization of adolescents with ADHD.

\section{References}

American Psychiatric Association. (2013). Diagnostic and Statistical Manual of Mental Disorders (5th ed.). Arlington, VA: American Psychiatric Publishing.

Amador Campos, J. A., Forns Santacana, M., Guàrdia-Olmos, J., \& Peró Cebollero, M. (2006). Estructura factorial y datos descriptivos del perfil de atención y del cuestionario TDAH para niños en edad escolar [Factor structure and descriptive 
data of Attention profile and ADHD questionnaire for school age children]. Psicothema, 18, 696-703.

Barkley, R. A. (2006). Attention-Deficit Hyperactivity Disorder: A handbook for diagnosis and treatment (3rd ed.). New York: Guilford Press.

Barkley, R. A. (2012). Barkley Deficits in Executive Functioning Scale-Children and Adolescents (BDEFS-CA). New York: Guilford Press.

Barkley, R. A., \& Murphy, K. R. (2006). Attention-Deficit Hyperactivity Disorders. A Clinical Workbook. (3rd ed.). New York: Guilford Press.

Barkley, R. A., \& Murphy, K. R. (2011). The nature of executive function (EF) deficits in daily life activities in adults with ADHD and their relationship to performance on EF tests. Journal of Psychopathology and Behavioral Assessment, 33, 137158. http://dx.doi.org/10.1007/s10862-011-9217-x

Best, J. R., \& Miller, P. H. (2010). A Developmental Perspective on Executive Function. Child Development, 81, 1641-1660. http://dx.doi.org/10.1111/j.14678624.2010.01499.x

Blair, C., \& Razza, R. P. (2007). Relating effortful control, executive function, and false belief understanding to emerging math and literacy ability in kindergarten. Child development, 78, 647-663. http://dx.doi.org/10.1111/j.1467-8624.2007.01019.x

Bodnar, L. E., Prahme, M. C., Cutting, L. E., Denckla, M. B., \& Mahone, E. M. (2007). Construct validity of parent ratings of inhibitory control. Child neuropsychology, 13, 345-362. http://dx.doi.org/10.1080/09297040600899867

Brickenkamp, R., \& Zillmer, E. (1998). The d2 Test of Attention. (1st US ed.). Seattle, WA: Hogrefe \& Huber Publishers. 
Brydges, C. R., Reid, C. L., Fox, A. M., \& Anderson, M. (2012). A unitary executive function predicts intelligence in children. Intelligence, 40, 458-469. http://doi.org/10.1016/j.intell.2012.05.006

Cambridge Cognition. (1996). CANTAB. Cambridge, UK: Cambridge Cognition.

Chaytor, N., Schmitter-Edgecombe, M., \& Burr, M. (2006). Improving the ecological validity of executive functioning assessment. Archives of Clinical Neuropsychology, 21, 217-227. http://doi.org/10.1016/j.acn.2005.12.002

Chiang, HL., Huang, LW., Gau, SS., \& Shang, CY. (2013). Associations of symptoms and subtypes of attention-deficit hyperactivity disorder with visuospatial planning ability in youth. Research in Developmental Disabilities, 34, 29862995. http://dx.doi.org/10.1016/j.ridd.2013.06.020

Cohen, J. (1998). Statistical power analysis for the behavioral sciences (2nd edition). Hillsdale, NJ: Lawrence Earlbaum Associates.

Conners, C. K. (2008). Conners 3rd edition manual. Toronto, Ontario, Canada: MultiHealth Systems.

Conners, C. K. (2000). Conners' Continuous Performance Test user's manual. Toronto, Canada: Multi-Health Systems.

Corbett, B. A., Constantine, L. J., Hendren, R., Rocke, D., \& Ozonoff, S. (2009). Examining executive functioning in children with autism spectrum disorder, attention deficit hyperactivity disorder and typical development. Psychiatry Research, 166, 210-222. http://doi.org/10.1016/j.psychres.2008.02.005

Cortese, S., Ferrin, M., Brandeis, D., Buitelaar, J., Daley, D., Dittmann, R. W., ... European ADHD Guidelines Group (EAGG). (2015). Cognitive Training for Attention-Deficit/Hyperactivity Disorder: Meta-Analysis of Clinical and 
Neuropsychological Outcomes from Randomized Controlled Trials. Journal of the American Academy of Child and Adolescent Psychiatry, 54, 164-174. http://doi.org/10.1016/j.jaac.2014.12.010

Davidson, M. C., Amso, D., Anderson, L. C., \& Diamond, A. (2006). Development of cognitive control and executive functions from 4 to 13 years: Evidence from manipulations of memory, inhibition, and task switching. Neuropsychologia, 44, 2037-2078. http://dx.doi.org/10.1016/j.neuropsychologia.2006.02.006

Davidson, F., Cherry, K., \& Corkum, P. (2016). Validating the Behavior Rating Inventory of Executive Functioning for Children With ADHD and Their Typically Developing Peers. Applied Neuropsychology: Child, 5, 127-137. http://dx.doi.org/10.1080/21622965.2015.1021957

Delis, D. C. (2012). Delis rating of executive function (D-REF). Bloomington, MN: Pearson.

Dennis, M., Francis, D. J., Cirino, P. T., Schachar, R., Barnes, M. A., \& Fletcher, J. M. (2009). Why IQ is not a covariate in cognitive studies of neurodevelopmental disorders. Journal of the International Neuropsychological Society, 15, 331343. http://doi.org/10.1017/S1355617709090481

Dolan, M., \& Lennox, C. (2013). Cool and hot executive function in conduct-disordered adolescents with and without co-morbid attention deficit hyperactivity disorder: relationships with externalizing behaviours. Psychological Medicine, 43, 24272436. http://doi.org/10.1017/S0033291712003078

Döpfner, M., Hautmann, C., Görtz-Dorten, A., Klasen, F., Ravens-Sieberer, U., \& The BELLA study group. (2015). Long-term course of ADHD symptoms from childhood to early adulthood in a community sample. European Child \& 
Adolescent Psychiatry, 24, 665-673. http://dx.doi.org/10.1007/s00787-014-06348

Duggan, E. C., \& Garcia-Barrera, M. A. (2015). Intelligence and executive functioning. In J. A. Naglieri \& S. Goldstein (Eds.), Handbook of intelligence (pp. 435-458). New York, NY: Springer.

Emslie, H., Wilson, F. C., Burden, V., Nimmo-Smith, I., \& Wilson, B. A. (2003). Behavioural Assessment of the Dysexecutive Syndrome for Children (BADS-C). London, UK: Harcourt Assessment/The Psychological Corporation.

Engelhardt, L. E., Mann, F. D., Briley, D. A., Church, J. A., Harden, K. P., \& TuckerDrob, E. M. (2016). Strong genetic overlap between executive functions and intelligence. Journal of Experimental Psychology: General, 145, 1141-1159. http://dx.doi.org/10.1037/xge0000195

Faraone, S.V., Biederman, J., \& Mick, E. (2006). The age-dependent decline of attention deficit hyperactivity disorder: a meta-analysis of follow-up studies. Psychological Medicine, 36, 159-165. http://dx.doi.org/10.1017/S003329170500471X

Frazier, T. W., Demaree, H. A., \& Youngstrom, E. A. (2004). Meta-analysis of intellectual and neuropsychological test performance in attentiondeficit/hyperactivity disorder. Neuropsychology, 18, 543-555. http://dx.doi.org/10.1037/0894-4105.18.3.543

Geurts, H.M., Verté, S., Oosterlaan, J., Roeyers, H., \& Sergeant, J.A. (2005). ADHD subtypes: Do they differ in their executive functioning profile? Archives of Clinical Neuropsychology, 20, 457-477. http://dx.doi.org/10.1016/j.acn.2004.11.001 
Gioia, G. A., Isquith, P. K., Guy, S. C., \& Kenworthy, L. (2000). Behavior Rating Inventory of Executive Function. Odessa, FL: Psychological Assessment Resources.

Goldstein, S., Naglieri, J. A., Princiotta, D., \& Otero, T. M. (2013). Introduction: A History of Executive Functioning as a Theoretical and Clinical Construct. In S. Goldstein, \& J. A. Naglieri (Eds.), Handbook of Executive Functioning (pp. 312). New York, NY: Springer.

Greenberg, L. M. (1991). TOVA Manual. Minneapolis, MN: Author.

Hart, H., Radua, J., Nakao, T., Mataix-Cols, D., \& Rubia, K. (2013). Meta-analysis of functional magnetic resonance imaging studies of inhibition and attention in attention-deficit/hyperactivity disorder: exploring task-specific, stimulant medication, and age effects. JAMA Psychiatry, 70, 185-198. http://dx.doi.org/10.1001/jamapsychiatry.2013.277

Heaton, R. K., Chelune, G. J., Talley, J. L., Kay, G. G., \& Curtiss, G. (1993). Wisconsin Card Sorting Test (WCST) manual, revised and expanded. Odessa, FL: Psychological Assessment Resources.

Hoogman, M., Bralten, J., Hibar, D. P., Mennes, M., Zwiers, M. P., Schweren, L. S. J., ... Franke, B. (2017). Subcortical brain volume differences in participants with attention deficit hyperactivity disorder in children and adults: a cross-sectional mega-analysis. The lancet Psychiatry, 4, 310-319. http://dx.doi.org/10.1016/S2215-0366(17)30049-4

Isquith, P. K., Roth, R. M., \& Gioia, G. (2013). Contribution of Rating Scales to the Assessment of Executive Functions, Applied Neuropsychology: Child, 0, 1-8. http://dx.doi.org/10.1080/21622965.2013.748389 
Klenberg, L., Jämsä, S., Häyrinen, T., Lahti-Nuuttila, P., \& Korkman, M. (2010). The Attention and Executive Function Rating Inventory (ATTEX): Psychometric properties and clinical utility in diagnosing ADHD subtypes. Scandinavian Journal of Psychology, 51, 439-448. http://dx.doi.org/10.1111/j.14679450.2010.00812.x

Krikorian, R., Bartok, J., \& Gay, N. (1994). Tower of London procedure: a standard method and developmental data. Journal of clinical and experimental neuropsychology, 16, 840-850. http://dx.doi.org/10.1080/01688639408402697

Lambek, R., Tannock, R., Dalsgaard, S., Trillingsgaard, A., Damm, D., \& Thomsen, P. H. (2011). Executive dysfunction in school-age children with ADHD. Journal Attention Disorders, 15, 646-655. http://dx.doi.org/10.1177/1087054710370935

Long, E. C., Hill, J., Luna, B., Verhulst, B., \& Clark, D. B. (2015). Disruptive behavior disorders and indicators of disinhibition in adolescents: the BRIEF-SR, anti-saccade task, and D-KEFS color-word interference test. Journal of Adolescence, 44, 182-190. http://doi.org/10.1016/j.adolescence.2015.07.003

Loo, S. K., Humphrey, L. A., Tapio, T., Moilanen, I. K., McGough, J. J., McCracken, J. T., ...Smalley, S.L. (2007). Executive functioning among Finnish adolescents with attention-deficit/hyperactivity disorder. Journal of the American Academy of Child \& Adolescent Psychiatry, 46, 1594-1604. http://dx.doi.org/10.1097/chi.0b013e3181575014

Maedgen, J. W., \& Carlson, C. L. (2000). Social functioning and emotional regulation in the attention deficit hyperactivity disorder subtypes. Journal of Clinical Child Psychology, 29, 30-42. http://dx.doi.org/10.1207/S15374424jccp2901_4 
Martel, M., Nikolas, M., \& Nigg, J. T. (2007). Executive function in adolescents with ADHD. Journal of American Academy of Child and Adolescent Psychiatry, 46, 1437-1444. http://dx.doi.org/10.1097/chi.0b013e31814cf953

Martinussen, R., Hayden, J., Hogg-Johnson, S., \& Tannock, R. (2005). A meta-analysis of working memory impairments in children with attention-deficit/hyperactivity disorder. Journal of the American Academy of Child and Adolescent Psychiatry, 44, 377-384. http://dx.doi.org/10.1097/01.chi.0000153228.72591.73

Martinussen, R., \& Tannock, R. (2006). Working memory impairments in children with attention-deficit hyperactivity disorder with and without comorbid language learning disorders. Journal of clinical and experimental neuropsychology, 28, 1073-1094. http://dx.doi.org/10.1080/13803390500205700

Mayes, S. D., \& Calhoun, S. L. (2006). WISC-IV and WISC-III profiles in children with ADHD. Journal of Attention Disorders, 9, 486-493. http://dx.doi.org/ $10.1177 / 1087054705283616$

McCandless, S., \& O'Laughlin, L. (2007). The clinical utility of the Behavior Rating Inventory of Executive Function (BRIEF) in the diagnosis of ADHD. Journal of Attention Disorders, 10, 381-389. http://dx.doi.org/10.1177/1087054706292115

McConaughy, S. H., Ivanova, M. Y., Antshel, K., \& Eiraldi, R. B. (2009). Standardized Observational Assessment of Attention Deficit Hyperactivity Disorder Combined and Predominantly Inattentive Subtypes. I. Test Session Observations. School Psychology Review, 38, 45-66.

Miller, G. A., \& Chapman. J. P. (2001). Misunderstanding analysis of covariance. Journal of Abnormal Psychology 110, 40-48. http://dx.doi.org/10.1037//0021$843 X .110 .1 .40$ 
Mitrushina, M., Boone, K. B., Razani, J., \& D’Elia, L. F. (2005). Handbook of normative data for neuropsychological assessment. Oxford: Oxford University Press.

Miyake, A., Friedman, N. P., Emerson, M. J., Witzki, A. H., Howerter, A., \& Wager, T. D. (2000). The unity and diversity of executive functions and their contributions to complex "Frontal Lobe" tasks: a latent variable analysis. Cognitive Psychology, 41, 49-100. http://dx.doi.org/10.1006/cogp.1999.0734

Mullane, J. C., \& Corkum, P. V. (2007). The Relationship Between Working Memory, Inhibition, and Performance on the Wisconsin Card Sorting Test in Children With and Without ADHD. Journal of Psychoeducational Assessment, 25, 211221. http://dx.doi.org/10.1177/0734282906297627

Naglieri, J. A., \& Goldstein, S. (2013). Comprehensive Executive Function Inventory (CEFI). Toronto: Multi-Health Systems Inc.

Nigg, J. T., Blaskey, L. G., Huang-Pollock, C. L., \& Rappley, M. D. (2002). Neuropsychological Executive Functions and DSM-IV ADHD Subtypes. Journal of the American Academy of Child \& Adolescent Psychiatry, 41, 59-66. http://dx.doi.org/10.1097/00004583-200201000-00012

Nigg, J. T., Willcutt, E. G., Doyle, A. E., \& Sonuga-Barke, E. J. (2005). Causal heterogeneity in attention-deficit/hyperactivity disorder: Do we need neuropsychologically impaired subtypes? Biological Psychiatry, 57, 1224-1230. http://dx.doi.org/10.1016/j.biopsych.2004.08.025

Nyhus, E., \& Barcelo, F. (2009). The Wisconsin Card Sorting Test and the cognitive assessment of prefrontal executive functions: A critical update. Brain and Cognition, 71, 437-451. http://dx.doi.org/10.1016/j.bandc.2009.03.005 
Oosterlaan, J., \& Sergeant, J.A. (1998). Response inhibition and response reengagement in attention-deficit/hyperactivity disorder, disruptive, anxious and normal children. Behavioral Brain Research, 94, 33-43. https://doi.org/10.1016/S0166-4328(97)00167-8

Osterrieth, P. A. (1944). Le test de copie d'une figure complexe: contribution à l'étude de la perception et de la mémoire. Archives de Psychologie, 30, 206-356.

Owens, E.B., \& Hinshaw, S.P. (2016). Pathways from neurocognitive vulnerability to co-occurring internalizing and externalizing problems among women with and without attention-deficit/hyperactivity disorder followed prospectively for 16 years. Development and Psychopathology, 28, 1013-1031. http://dx.doi.org/10.1017/S0954579416000675

Owen, A. M., Downes, J. J., Sahakian, B. J., Polkey, C. E., \& Robbins, T. W. (1990). Planning and spatial working memory following frontal lobe lesions in man. Neuropsychologia, 28, 1021-1034. http://dx.doi.org/10.1016/00283932(90)90137-D

Petrides, M., \& Milner, B. (1982). Deficits on subject ordered tasks after frontal and temporal lobe lesions in man. Neuropsychologia, 20, 249- 262. https://doi.org/10.1016/0028-3932(82)90100-2

Pingault, J. B., Viding, E., Galéra, C., Greven, C. U., Zheng, Y., Plomin, R., \& Rijsdijk, F. (2015). Genetic and Environmental Influences on the Developmental Course of Attention-Deficit/Hyperactivity Disorder Symptoms From Childhood to Adolescence. Journal of the American Medical Association Psychiatry, 72, 651658. http://dx.doi.org/10.1001/jamapsychiatry.2015.0469 
Porteus, S. D. (1973). Porteus Maze Test: Fifty years application. Palo Alto, CA: Pacific Books.

Rauch, W. A., Gold, A., \& Schmitt, K. (2012). Combining Cognitive and Personality Measures of Impulse Control in the Assessment of Childhood ADHD. European Journal of Psychological Assessment, 28, 208-215. http://dx.doi.org/10.1027/1015-5759/a000128

Reitan, R. M. (1992). Trail Making Test: Manual for administration and scoring. Tucson, AZ: Reitan Neuropsychology Laboratory.

Rey, A. (1941). L'examen psychologique dans les cas d'encéphalopathie traumatique. Archives de Psychologie, 28, 286-340.

Riccio, C. A, Homack, S., Jarratt, K. P., \& Wolfe, M. (2006). Differences in academic and executive function domains among children with ADHD predominantly inattentive and combined types. Archives of Clinical Neuropsychology, 21, 657-667.http://dx.doi.org/10.1016/j.acn.2006.05.010

Rinsky, J., \& Hinshaw, S. P. (2011). Linkages between childhood executive functioning and adolescent social functioning and psychopathology in girls with ADHD. Child Neuropsychology, 4, 368-390. http://dx.doi.org/10.1080/09297049.2010.544649

Roberts, B. A., Martel, M. M., \& Nigg, J. T. (2017). Are There Executive Dysfunction Subtypes within Attention-Deficit/Hyperactivity Disorder? Journal of Attention Disorders, 21, 284-293. http://doi.org/10.1177/1087054713510349

Rosenthal, E. N., Riccio, C.A., Gsanger, K.M., \& Jarratt, K.P. (2006). Digit Span components as predictors of attention problems and executive functioning in 
children. Archives of Clinical Neuropsychology, 21, 131-139.

http://dx.doi.org/10.1016/j.acn.2005.08.004

Seidman, L. J. (2006). Neuropsychological functioning in people with ADHD across the lifespan. Clinical Psychology Review, 26, 466-485.

http://dx.doi.org/10.1016/j.cpr.2006.01.004

Semrud-Clikeman, M., Walkowiak, J., Wilkinson, A., \& Butcher, B. (2010). Executive functioning in children with Asperger syndrome, ADHD-combined type, ADHD-predominately inattentive type, and controls. Journal of Autism and Developmental Disorders, 40, 1017-1027. http://dx.doi.org/10.1007/s10803$010-0951-9$

Sheslow, D., \& Adams, W. (2003). Wide Range Assessment of Memory and Learning (2nd ed.). Wilmington, DE: Wide Range.

Shimoni, M., Engel-Yeger, B., \& Tirosh, E. (2012). Executive dysfunctions among boys with Attention Deficit Hyperactivity Disorder (ADHD): Performancebased test and parents report. Research in Developmental Disabilities, 33, 85865. http://dx.doi.org/10.1016/j.ridd.2011.12.014

Silver, C. H. (2014). Sources of data about children's executive functioning: Review and commentary. Child Neuropsychology, 20, 1-13. http://doi.org/ $10.1080 / 09297049.2012 .727793$

Skogli, E. W., Egeland, J., Andersen, P. N., Hovik, K. T., \& Øie, M. (2014). Few differences in hot and cold executive functions in children and adolescents with combined and inattentive subtypes of ADHD. Child Neuropsychology, 20, 162181. http://doi.org/10.1080/09297049.2012.753998 
Snyder, H. R., Miyake, A., \& Hankin, B. L. (2015). Advancing understanding of executive function impairments and psychopathology: bridging the gap between clinical and cognitive approaches. Frontiers in Psychology, 6, 328. http://doi.org/10.3389/fpsyg.2015.00328

Solanto, M. V., Gilbert, S. N., Raj, A., Zhu, J., Pope-Boyd, S., Stepak, B., ...Newcorn, J. H. (2007). Neurocognitive functioning in $\mathrm{AD} / \mathrm{HD}$, predominantly inattentive and combined subtypes. Journal of Abnormal Child Psychology, 35, 729-744. http://dx.doi.org/10.1007/s10802-007-9123-6

Sowerby, P., Seal, S., \& Tripp, G. (2011). Working Memory Deficits in ADHD: The Contribution of Age, Learning/Language Difficulties, and Task Parameters. Journal Attention Disorders, 15, 461-472. http://dx.doi.org/10.1177/1087054710370674

Strauss, E., Sherman, E. M. S., \& Spreen, O. (2006). A compendium of neuropsychological tests (3rd ed.). New York: Oxford University Press.

Thaler, N. S., Bello, D. T., \& Etcoff, L. M. (2013). WISC-IV profiles are associated with differences in symptomatology and outcome in children with ADHD. Journal of Attention Disorders, 17, 291-301. http://dx.doi.org/10.1177/1087054711428806

Toplak, M. E., Bucciarelli, S. M., Jain, U., \& Tannock, R. (2009). Executive functions: Performance-based measures and the behavior rating inventory of executive function (BRIEF) in adolescents with attention deficit/hyperactivity disorder (ADHD). Child neuropsychology, 15, 53-72. http://dx.doi.org/10.1080/09297040802070929 
Toplak, M. E., West, R., F., \& Stanovich, K. E. (2013). Practitioner review: Do performance-based measures and ratings of executive function assess the same construct? Journal of Child Psychology and Psychiatry, 54, 113-224. http://dx.doi.org/10.1111/jcpp.12001

Toplak, M. E., West, R. F., \& Stanovich, K. E. (2017). The assessment of executive functions in Attention-Deficit/Hyperactivity Disorder (ADHD): PerformanceBased measures versus ratings of behavior. In M. Hoskyn, G. Iarocci, \& A. Young (Eds.), Executive functions in children's everyday lives: A handbook for professionals in applied psychology. New York: Oxford University Press.

Turgay, A., Ginsberg, L., Sarkis, E., Jain, R., Adeyi, B., Gao, J., ...Findling, R. L. (2010). Executive function deficits in children with attention deficit/hyperactivity disorder and improvement with lisdexamfetamine dimesylate in an open-label study. Journal of child and adolescent psychopharmacology, 20, 503-511. http://dx.doi.org/10.1089/cap.2009.0110

Vriezen, E. R., \& Pigott, S. E. (2002). The relationship between parental report on the BRIEF and performance-based measures of executive function in children with moderate to severe traumatic brain injury. Child Neuropsychology. 8, 296-303. http://dx.doi.org/10.1076/chin.8.4.296.13505

Waber, D., Gerber, E., Turcios, V., Wagner, E., \& Forbes, P. (2006). Executive functioning and performance on high-stakes testing in children from urban schools. Developmental Neuropsychology, 29, 459-477. http://dx.doi.org/ 10.1207/s15326942dn2903_5

Wählstedt, C., Thorell, L. B., \& Bohlin, G. (2009). Heterogeneity in ADHD: neuropsychological pathways, comorbidity and symptom domains. Journal of 
Abnormal Child Psychology, 37, 551-564. http://dx.doi.org/10.1007/s10802008-9286-9

Wechsler, D. (2005). WISC-IV. Escala de inteligencia de Wechsler para niños IV. Madrid: TEA Ediciones.

Wechsler, D., \& Naglieri, J. (2011). Escala no verbal de aptitud intelectual de Wechsler. Madrid: Pearson.

Weyandt, L.L., Oster, D. R., Gudmundsdottir, B.G., DuPaul, G. J., \& Anastopoulos, A. D. (2017). Neuropsychological functioning in college students with and without ADHD. Neuropsychology, 31, 160-172. http://dx.doi.org/10.1037/neu0000326

Willcutt, E. G., Doyle, A. E., Nigg, J. T., Faraone, S. V., \& Pennington, B. F. (2005). Validity of the executive function theory of attention-deficit/hyperactivity disorder: a meta-analytic review. Biological Psychiatry. 57, 1336-1346. http://dx.doi.org/10.1016/j.biopsych.2005.02.006

Wilson, B. A., Alderman, N., Burgess, P. W., Emslie, H., \& Evans, J. J. (1996). Behavioral Assessment of the Dysexecutive Syndrome. Bury St. Edmund, UK: Thames Valley Test Company.

Yoshimasu, K., Barbaresi, W. J., Colligan, R. C., Voigt, R. G., Killian, J. M., Weaver, A. L., \& Katusic, S. K. (2012). Childhood ADHD is strongly associated with a broad range of psychiatric disorders during adolescence: a population-based birth cohort study. Journal of Child Psychology and Psychiatry, and Allied Disciplines, 53, 1036-1043. http://doi.org/10.1111/j.1469-7610.2012.02567.x 


\section{EXECUTIVE FUNCTION IN ADHD IN ADOLESCENTS}

Table 1

Summary of cognitive EF measures

\begin{tabular}{|c|c|c|}
\hline Cognitive EF & Performance-based task & Score type \\
\hline Working & $\begin{array}{l}\text { Spatial span (SSp) of Wechsler Nonverbal } \\
\text { scale of ability (WNV) }\end{array}$ & SSp: Forward and Backward \\
\hline memory & $\begin{array}{l}\text { Rey-Osterrieth Complex Figure Test } \\
\text { (ROCF) }\end{array}$ & Immediate recall accuracy \\
\hline \multirow[b]{2}{*}{ Planning } & ROCF & $\begin{array}{l}\text { Copy accuracy } \\
\text { Copy time }\end{array}$ \\
\hline & Porteus Maze Test (PMT) & $\begin{array}{l}\text { Planning time (seconds) before beginning to } \\
\text { draw (mazes V to XIV) } \\
\text { Total Q score (Age quotient) }\end{array}$ \\
\hline \multirow{3}{*}{ Flexibility } & Wisconsin Card Sorting Test (WCST) & $\begin{array}{l}\text { Perseverative errors } \\
\text { Conceptual level responses } \\
\text { Number of categories completed }\end{array}$ \\
\hline & Trail Making Test (TMT) & Total time in seconds' part B \\
\hline & PMT & Qualitative $Q$ score \\
\hline Inhibition & d2 Test of Attention & $\begin{array}{l}\text { Commission errors } \\
\text { Total test effectiveness }\end{array}$ \\
\hline
\end{tabular}

Note. Neuropsychological measures were grouped according to the hypothetical underlying cognitive process that they engage (Mitrushina, Boone, Razani, \& D’Elia, 2005; Strauss, Sherman, \& Spreen, 2006). 


\section{EXECUTIVE FUNCTION IN ADHD IN ADOLESCENTS}

Table 2

Demographic and Descriptive Statistic for ADHD and control groups on ADHD symptoms measures

\begin{tabular}{lcccc}
\hline & ADHD-I $(1)$ & ADHD-C $(2)$ & CG $(3)$ & \\
& $(n=48)$ & $(n=27)$ & $(n=43)$ & \\
& Mean $(S D)$ & Mean $(S D)$ & Mean $(S D)$ & $F / \chi^{2}$ \\
\hline Age & $13.83(1.36)$ & $13.19(1.14)$ & $13.42(1.38)$ & 2.33 \\
Gender/males (\%) & $34(70.8 \%)$ & $17(63 \%)$ & $24(55.8 \%)$ & 2.21 \\
Parent Conners-3 & & & & \\
DSM Inattentive scale & $73.69(9.45)^{\mathrm{a}}$ & $72.59(8.11)^{\mathrm{a}}$ & $46.33(9.02)^{\mathrm{b}}$ & $97.56^{*}$ \\
DSM Hyperactive-Impulsive scale & $60.85(14.56)^{\mathrm{b}}$ & $81.22(9.94)^{\mathrm{a}}$ & $48.74(9.02)^{\mathrm{c}}$ & $46.46^{*}$ \\
Conners-3 ADHD Index & $65.96(12.74)^{\mathrm{b}}$ & $78.93(11.50)^{\mathrm{a}}$ & $48.95(8.85)^{\mathrm{c}}$ & $63.45^{*}$ \\
Teacher Conners-3 & & & & \\
DSM Inattentive scale & & & & \\
DSM Hyperactive-impulsive scale & $76.94(10.79)^{\mathrm{a}}$ & $76.85(8.25)^{\mathrm{a}}$ & $47.35(8.71)^{\mathrm{b}}$ & $118.33^{*}$ \\
Conners-3 ADHD Index & $57.44(11.92)^{\mathrm{b}}$ & $79.07(12.21)^{\mathrm{a}}$ & $49.33(10.05)^{\mathrm{c}}$ & $56.78^{*}$ \\
Self-report Conners-3 & $66.71(11.58)^{\mathrm{b}}$ & $83.96(8.71)^{\mathrm{a}}$ & $50.30(11.01)^{\mathrm{c}}$ & $82.15^{*}$ \\
DSM Inattentive scale & & & \\
DSM-IV Hyperactive-Impulsive scale & & & \\
\hline
\end{tabular}

Note. $A D H D=$ attention deficit hyperactivity disorder; $A D H D-I=$ predominantly inattentive; $A D H D-C=$ combined; $C G=$ control group. Superscripts $(a, b, c)=$ denote subgroup differences after Bonferroni adjustment for multiple comparisons; different letters indicate statistically significant differences between groups $(a>b>c)$ and the same letters indicate no significant differences between the groups.

${ }^{*} p<.001$.

URL: http://mc.manuscriptcentral.com/ncny Email: westerm@msn.com 


\section{EXECUTIVE FUNCTION IN ADHD IN ADOLESCENTS}

Table 3

Descriptive statistics for ADHD-I, ADHD-C and Control groups on cognitive factors and behavior EF measures, MANOVAs and post-hoc comparisons

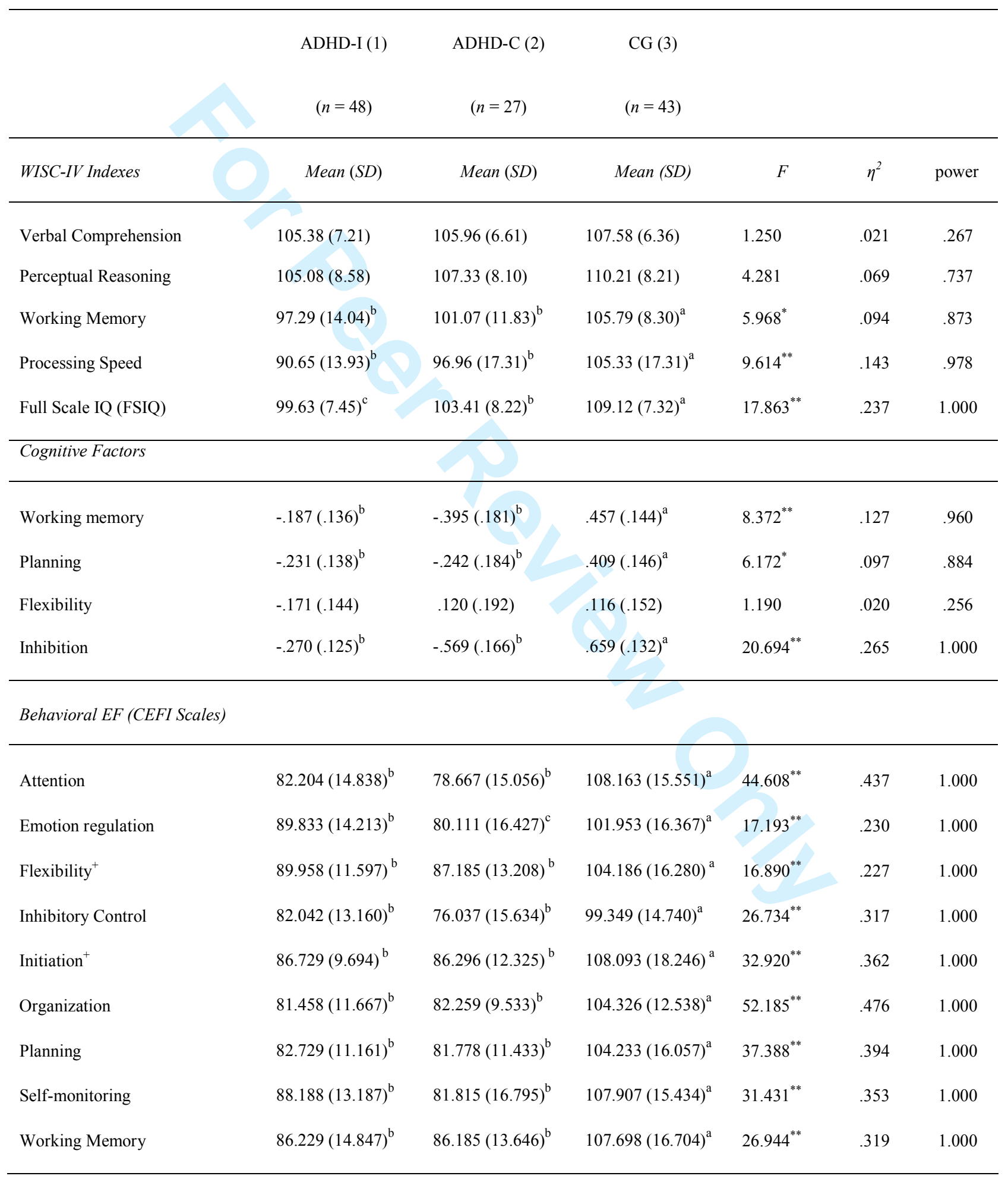




\title{
EXECUTIVE FUNCTION IN ADHD IN ADOLESCENTS
}

\begin{abstract}
Note. $A D H D=$ attention deficit hyperactivity disorder; $A D H D-I=$ predominantly inattentive; $A D H D-C=$ combined; $C G=$ control group; $\eta^{2}=$ partial eta-squared; power = power observed. Superscripts $(\mathrm{a}, \mathrm{b}, \mathrm{c})=$ denote subgroup differences after Bonferroni or Games-Howell (+) adjustment for multiple comparisons $\left({ }^{*} p<.01 ;{ }^{* *} p<.001\right)$; different letters indicate statistically significant differences between groups $(a>b>c)$ and the same letters indicate no significant differences between the groups.
\end{abstract}




\section{EXECUTIVE FUNCTION IN ADHD IN ADOLESCENTS}

Table 4

ADHD group correlations (below diagonal) and Control group correlations (above diagonal) between cognitive and behavioral EF measures and inattentive and hyperactive/impulsive symptoms of Conners-3 self-rating (DSM scales)

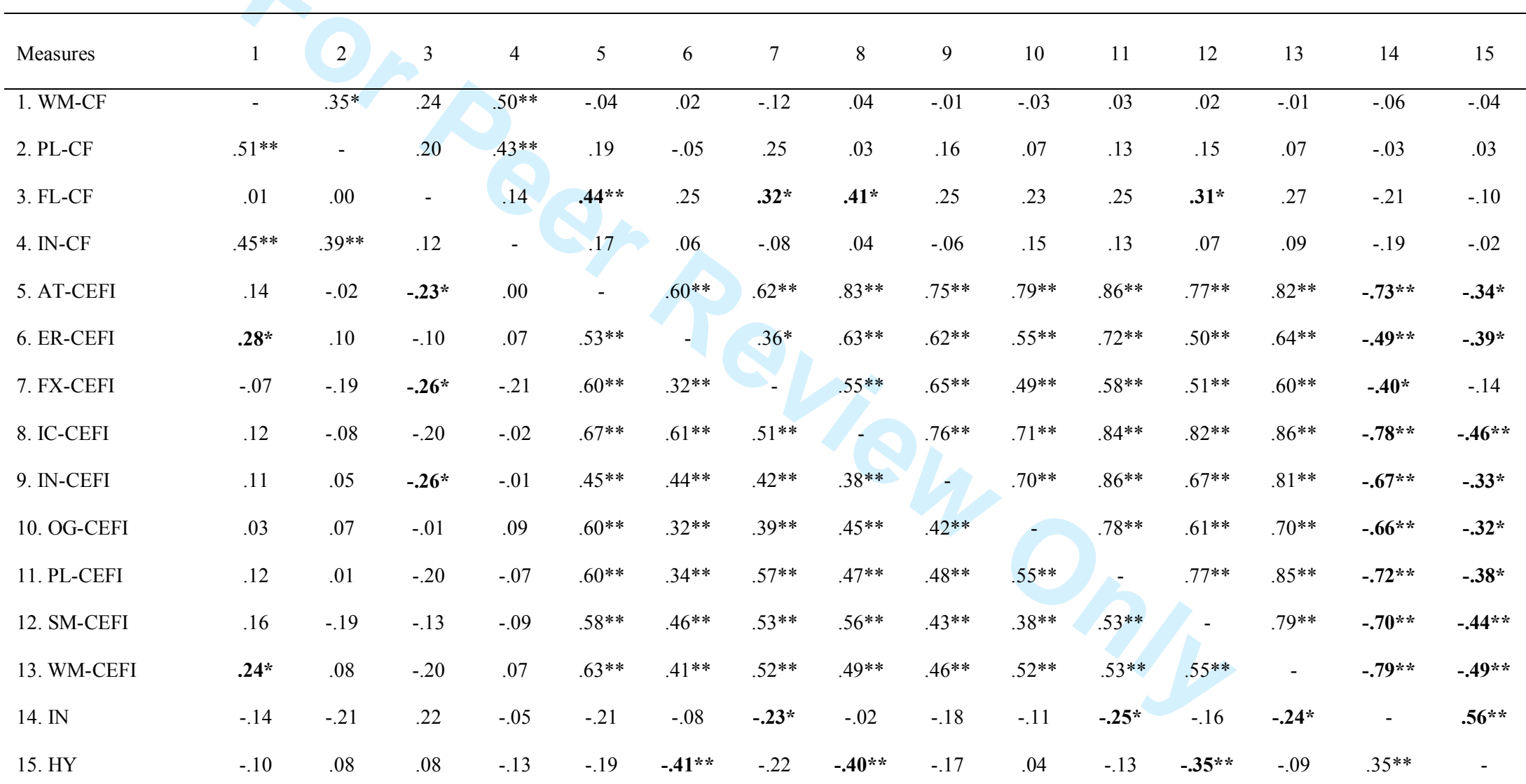




\section{EXECUTIVE FUNCTION IN ADHD IN ADOLESCENTS}

Note. $A D H D=$ attention deficit hyperactivity disorder; $C F=$ Cognitive Factors: $W M=$ Memory Working, $P L=$ Planning, $F X=$ Flexibility, $I N=$ Inhibition; CEFI: $A T=$ Attention, $E R=$ Emotion regulation, $F X=$ Flexibility, $I C=$ Inhibitory Control, $I N=$ Initiation, $O G=$ Organization, $P L=$ Planning, $S M=$ Self-monitoring, $W M$

= Working Memory; $I N=$ Conners-3 DSM ADHD Inattentive Scale, $H Y=$ Conners-3 DSM ADHD Hyperactive/Impulsive Scale. In bold type the significant correlations between ADHD symptoms, cognitive and behavioral EF.

${ }^{*} p<.05{ }^{* *} p<.01$. 


\section{EXECUTIVE FUNCTION IN ADHD IN ADOLESCENTS}




\section{EXECUTIVE FUNCTION IN ADHD IN ADOLESCENTS}

Table 5

Summary of significant hierarchical regression analysis for cognitive EF factors predicting CEFI scales

\begin{tabular}{|c|c|c|c|c|c|c|}
\hline & \multicolumn{3}{|c|}{$\begin{array}{l}\text { ADHD Group } \\
\quad(n=75)\end{array}$} & \multicolumn{3}{|c|}{$\begin{array}{l}\text { Control Group } \\
\qquad(n=43)\end{array}$} \\
\hline & B & $S E B$ & $\beta$ & B & $S E B$ & $\beta$ \\
\hline \multicolumn{7}{|l|}{ CEFI Attention scale } \\
\hline \multicolumn{7}{|l|}{ Step 1} \\
\hline Constant & 81.189 & 1.914 & & 105.877 & 3.258 & \\
\hline Working memory & 2.771 & 2.013 & .181 & -3.005 & 3.304 & -.162 \\
\hline Inhibition & -1.334 & 2.121 & -.083 & 5.549 & 3.894 & .254 \\
\hline \multicolumn{7}{|l|}{ Step 2} \\
\hline Constant & 80.003 & 1.885 & & 105.919 & 2.944 & \\
\hline Working memory & 3.282 & 2.172 & .214 & -5.323 & 3.073 & -.287 \\
\hline Inhibition & -.346 & 2.153 & -.021 & 4.409 & 3.703 & .201 \\
\hline Planning & -1.881 & 2.093 & -.123 & 2.169 & 2.938 & .117 \\
\hline Flexibility & -3.305 & 1.672 & -.230 & 7.600 & 2.418 & $.454 * *$ \\
\hline \multicolumn{7}{|c|}{ CEFI Emotion regulation scale } \\
\hline \multicolumn{7}{|l|}{ Step 1} \\
\hline Constant & 87.247 & 1.951 & & 101.070 & 3.511 & \\
\hline Working memory & 4.987 & 2.052 & $.310^{*}$ & -.116 & 3.560 & -.006 \\
\hline Inhibition & -1.185 & 2.163 & -.070 & 1.420 & 4.197 & .062 \\
\hline \multicolumn{7}{|l|}{ Step 2} \\
\hline Constant & 87.175 & 1.975 & & 101.336 & 3.468 & \\
\hline Working memory & 5.175 & 2.275 & .322 & -.897 & 3.620 & -.046 \\
\hline Inhibition & -.797 & 2.256 & -.047 & 2.262 & 4.362 & .098 \\
\hline Planning & -.715 & 2.193 & -.045 & -2.511 & 3.460 & -.128 \\
\hline Flexibility & -1.323 & 1.751 & -.088 & 4.873 & 2.847 & .277 \\
\hline \multicolumn{7}{|c|}{ CEFI Flexibility scale } \\
\hline \multicolumn{7}{|l|}{ Step 1} \\
\hline Constant & 88.070 & 1.536 & & 105.494 & 3.471 & \\
\hline
\end{tabular}




\section{EXECUTIVE FUNCTION IN ADHD IN ADOLESCENTS}

Working memory

Inhibition

Step 2

Constant

Working memory

Inhibition

Planning

Flexibility

CEFI Self-monitoring scale

Step 1

Constant

Working memory

Inhibition

Step 2

Constant

Working memory

Inhibition

Planning

Flexibility
.472

$-2.985$

87.865

1.221

$-1.979$

$-2.348$

$-2.865$
1.613

1.703

1.495

1.722

.098

1.707

$-.151$

1.660

$-.190$

$1.325-.246^{*}$
105.218

$-4.843$

$-3.279$

6.590

5.567

3.519

$-.115$

$4.149 \quad-.019$

3.168

$3.307-.249$

$3.984-.143$

$3.161 \quad .338^{*}$

$218^{*}$

$\begin{array}{llllll}85.623 & 1.864 & & 106.931 & 3.511 & \\ 3.916 & 1.960 & .258 & -.282 & 3.355 & -.015 \\ -3.354 & 2.066 & -.210 & 1.675 & 3.955 & .077\end{array}$

$\begin{array}{llcccc}85.265 & 1.797 & & 106.926 & 3.219 & \\ 6.023 & 2.070 & .397 * & -.1 .926 & 3.360 & -.105 \\ -.1 .969 & 2.053 & -.123 & .699 & 4.049 & .032 \\ -5.274 & 1.996 & -.348 * * & 1.983 & 3.212 & .107 \\ -1.611 & 1.594 & -.113 & 5.077 & 2.643 & .306\end{array}$

Note. $A D H D=$ attention deficit hyperactivity disorder; $\mathrm{B}=$ un-standardized beta coefficient; $E S B=$ standard error; $\beta=$ standardized beta coefficient.

$* p<.05, * * p<.01$ 